\title{
Environmental safety in the implementation of carbon dioxide geological storage technologies in the Donbass
}

\author{
Fedor Nedopekin ${ }^{1}$, Nikolay Shestavin ${ }^{1, *}$ and Viktoriya Yurchenko ${ }^{1}$ \\ ${ }^{1}$ Donetsk National University, 24 Universitetskaya str., Donetsk, 83001, Ukraine
}

\begin{abstract}
The Donbass has the largest potential in Europe for the geological storage of carbon dioxide $\left(\mathrm{CO}_{2}\right)$, which needs to be implemented on a large scale to mitigate the effects of global climate change. The environmental risks of $\mathrm{CO}_{2}$ leaks in the processes of capturing, transporting and geological storage of $\mathrm{CO}_{2}$ at the enterprises of the energy and industrial sectors of the economy of the eastern regions of Ukraine are analyzed. Geographic information systems have been created in these areas with layers of geological structures suitable for long-term storage of supercritical $\mathrm{CO}_{2}$. The impact of $\mathrm{CO}_{2}$ leaks from geological repositories on the environment is estimated. In the proposed $\mathrm{CO}_{2}$ storage areas, some $\mathrm{CO}_{2}$ leakage scenarios were analyzed due to the filtering of $\mathrm{CO}_{2}$ fluids through porous rock layers, through abandoned wells and tectonic faults of the Donbas geological structures. The potential effects of $\mathrm{CO}_{2}$ leakage on groundwater quality in the region are also assessed.
\end{abstract}

Current global climate change is caused [1], to a large extent, by an increase in the amount of greenhouse gases in the atmosphere, mainly carbon dioxide $\left(\mathrm{CO}_{2}\right)$. The main anthropogenic source of $\mathrm{CO}_{2}$ emissions is energy and industrial enterprises, which widely use fossil fuel combustion, which causes great environmental risks for the environment [2].

Studies of ways to mitigate the effects of global climate change [3,4] indicate the need in the near future to significantly reduce $\mathrm{CO}_{2}$ emissions into the atmosphere through the implementation of $\mathrm{CO}_{2}$ capture and storage (CCS) technologies. The use of these technologies will ensure by 2050 a decrease in the expected average increase in the global temperature of the atmosphere by $2^{\circ} \mathrm{C}$. The large-scale implementation of CCS technologies requires significant material and financial resources, which will lead to an increase in electricity prices by an average of $30 \%$ - however, so far there is no other effective way to reduce the amount of $\mathrm{CO}_{2}$ in the atmosphere and CCS technologies need to be implemented in all countries of the world.

At present, several thermal power plants with installed $\mathrm{CO}_{2}$ capture units before combustion, during oxygen combustion and after fuel combustion are already under construction and are operating in a number of countries (Australia, Germany, Spain, etc.). The captured $\mathrm{CO}_{2}$ is then transferred to a liquid supercritical state and transported to the place of geological storage in rocks at a depth of more than $800 \mathrm{~m}$.

${ }^{*}$ Corresponding author: $\underline{\text { msshest } @ \text { gmail.com }}$ 
The introduction of CCS technologies in the energy and other industries will temporarily mitigate the effects of climate change before developing climate-friendly energy sources. But when using technologies CCS, there are risks of $\mathrm{CO}_{2}$ leakage, which can have an adverse effect on humans and the environment.

The territory of Donbass has the most significant potential [5] in Europe (Fig. 1) for geological storage of $\mathrm{CO}_{2}$ in order to mitigate the effects of climate change [6]. This potential for $\mathrm{CO}_{2}$ accumulation is estimated at 45.7 to 428.3 billion tonnes, which causes interest in the possibility of using it for the needs of the whole of Europe, but it should take into account the great environmental risks of geological storage of $\mathrm{CO}_{2}$ for the territory of Donbass.

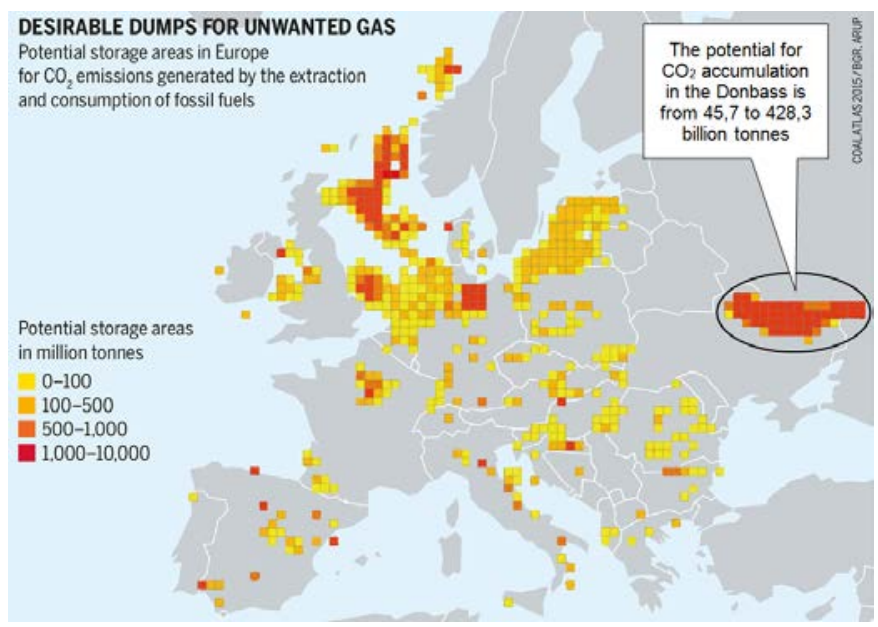

Fig. 1. Potential areas for $\mathrm{CO}_{2}$ accumulation in Europe [5]

Geological structures of Donbass [7] have been identified previously, suitable for longterm storage of supercritical $\mathrm{CO}_{2}$, which is transported through the existing gas transmission system with some upgrades, and then pumped into the Paleozoic sediments of Donbass [8] in several promising areas (Fig. 2) that are not contain territories of large settlements, operating coal mines and areas of tectonic disturbances in the form of salt rods.

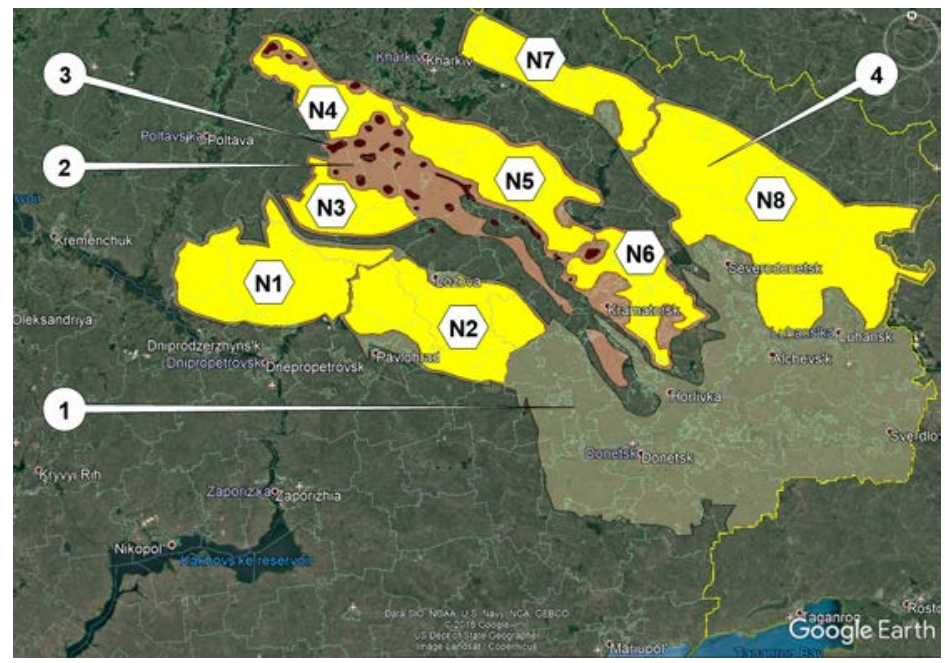

Fig. 2. Localization of promising zones and areas of $\mathrm{CO}_{2}$ geological storage in the Donbass 
In Fig. 2 the following territories are identified, which are determined on the basis of studies of archival documentation on the geological structure of Donbass [8]:

1 - Carboniferous sediment zone;

2 - zones of Permian salt deposits;

3 - Devon salt stocks;

4 - eight promising areas for the geological storage of $\mathrm{CO}_{2}(\mathrm{~N} 1-\mathrm{N} 8)$.

The purpose of this study is to determine the likely scenarios for $\mathrm{CO}_{2}$ leakage from prospective geological storage sites and assess the risk of $\mathrm{CO}_{2}$ leakage through abandoned wells and tectonic faults, as well as to assess the impact of $\mathrm{CO}_{2}$ leaks on the groundwater quality of the region using the example of the largest geological site for $\mathrm{CO}_{2}$ storage in the north Donbass.

Possible $\mathrm{CO}_{2}$ leaks in the processes of its capture and transportation will be of an emergency nature, therefore they should be easily identified and repaired. $\mathrm{CO}_{2}$ leaks from underground storage are difficult to predict and difficult to detect. Therefore, the territories in which promising areas of geological storage of $\mathrm{CO}_{2}$ will be located have risks of a negative impact on humans and the environment.

In the process of $\mathrm{CO}_{2}$ injection and storage, three scenarios of $\mathrm{CO}_{2}$ leaks from its geological storage sites can be implemented mainly [3]:

- leakage due to insufficient tightness of the rock-tire;

- leakage of abandoned and existing wells, trunks, drifts;

- leakage through existing faults and cracks in mountain formations.

Other scenarios of $\mathrm{CO}_{2}$ leaks are possible in the form of combinations of these three main scenarios, and the negative impact on humans and the environment will only increase.

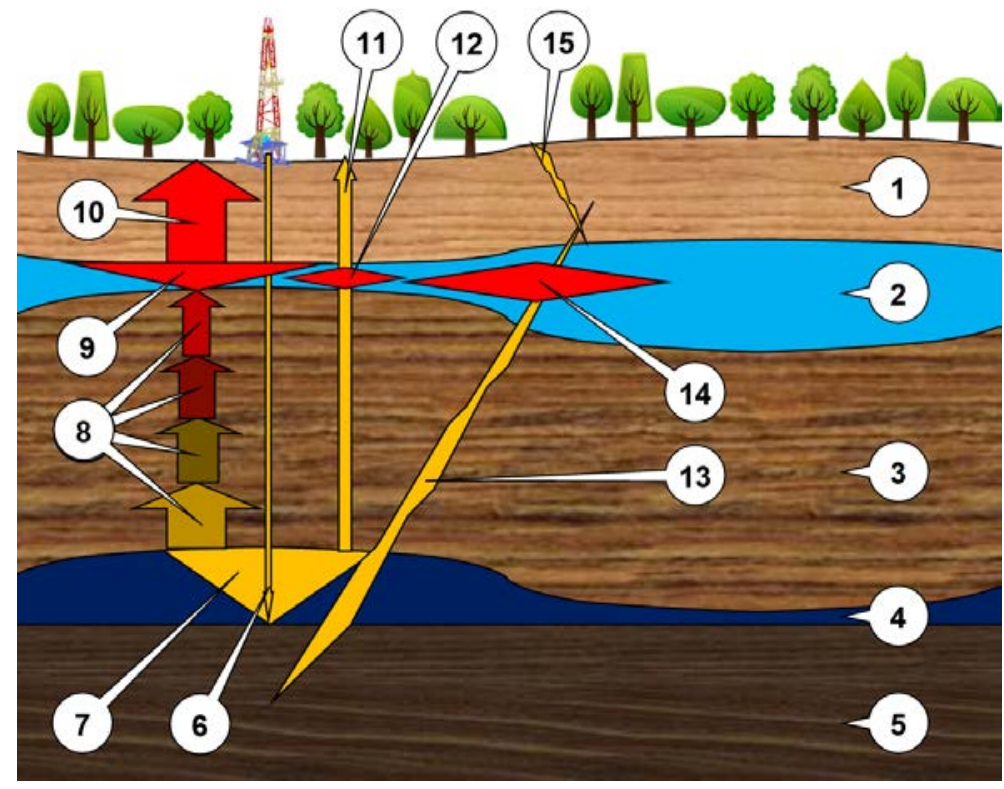

Fig. 3. The scheme of the implementation of $\mathrm{CO}_{2}$ leaks from the geological repository

In Fig. 3 shows a simplified diagram of these three scenarios of $\mathrm{CO}_{2}$ leaks from geological repositories, where the following details are indicated:

1 - the surface layer of soil with a thickness of about 50-100 m;

2 - groundwater;

3 - various layers of geological structures, including a high-density tire formation, located deeper than $800 \mathrm{~m}$;

4 - aquifers or sedimentary rocks that are able to accumulate supercritical $\mathrm{CO}_{2}$; 
5 - rocks of deeper geological layers, located deeper than $\mathrm{CO}_{2}$ storage areas;

6 - well for injection of supercritical $\mathrm{CO}_{2}$ into its storage area;

7 - zone of distribution and storage of fluid $\mathrm{CO}_{2}$ under the impermeable rock-cap.

Positions 8, 9 and 10 in Fig. 3 correspond to the implementation of the first scenario of $\mathrm{CO}_{2}$ leakage due to the lack of tightness of the rock-tire. Estimates of $\mathrm{CO}_{2}$ leakage volumes in this scenario are carried out by numerical simulation of thermo-hydrodynamic and mechanical-chemical processes [9], taking into account the real parameters and composition of rocks located above the $\mathrm{CO}_{2}$ storage area. These processes (8) proceed very slowly (it may take 100 or 1000 years until the product of the processes reaches the groundwater or surface), but it is extremely dangerous for humans and the environment (supercritical $\mathrm{CO}_{2}$, both liquid and two-phase, is a very effective solvent of rocks and products of such chemical reactions may be toxic). And getting into the groundwater (9) such toxic products can significantly impair their quality. Then these products and gaseous $\mathrm{CO}_{2}$ reach the surface (10) and can adversely affect humans and the environment.

The second scenario of $\mathrm{CO}_{2}$ leakage can be realized in the area of developed and existing oil and gas fields. There are many such deposits in the Donbass, some of which continue to be exploited [10], and some are conserved or abandoned, although hydrocarbons still remain there. In order to increase oil and gas recovery from seams, you can use $\mathrm{CO}_{2}$ injections as part of projects on the implementation of CCS technologies in the Donbass.

Positions 11 and 12 in Fig. 3 correspond to this scenario of $\mathrm{CO}_{2}$ leakage from geological storages, while in the process of raising $\mathrm{CO}_{2}$ to the surface through abandoned and operating wells (11), it can be dissolved in groundwater (12), which will affect their quality.

Since the abandoned and operating wells are located near or on the territory of oil and gas fields, it is possible to estimate the risks of $\mathrm{CO}_{2}$ leakage in this way by comparing the areas of fields and areas of prospective geological storage of $\mathrm{CO}_{2}$.

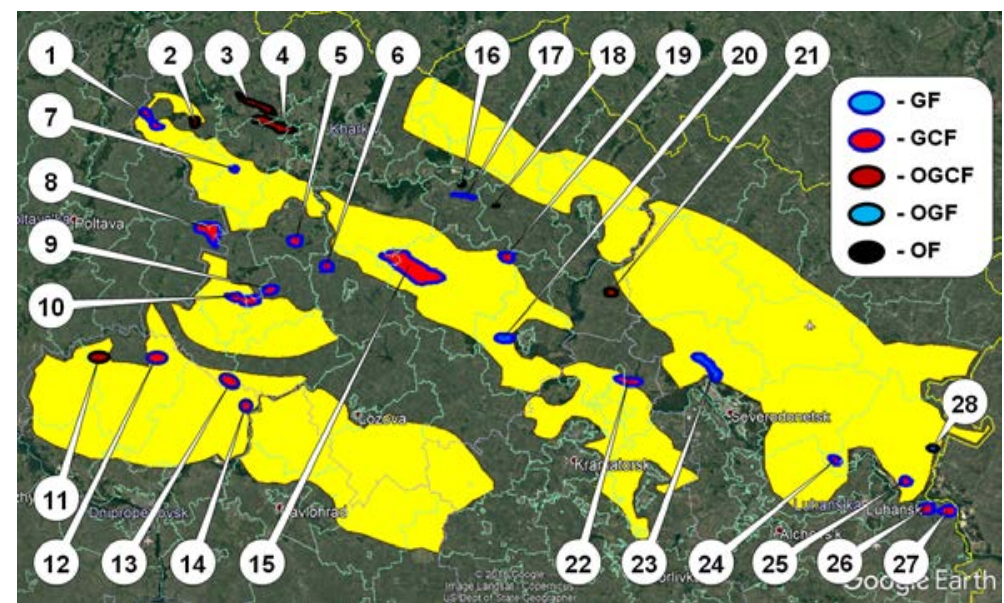

Fig. 4. Localization of gas (GF), gas condensate (GCF), oil and gas condensate (OGCF), oil and gas (OGF) and oil (OF) fields

The Fig. 4 shows following oil and gas fields of Donbass [10] are shown: 1 Berezovskoe GCF; 2 - Sakhalinskoe OGCF; 3 - Skvortsovskoe OGCF; 4 - Yulievskoe OGCF; 5 - Melikhovskoe GCF; 6 - Efremovskoe GCF; 7 - Kolomakskoe GF; 8 - Zap.Krestischenskoe GCF; 9 - Kegichevskoe GCF; 10 - Kobzevskoe GCF; 11 - Kremenovskoe OGCF; 12 - Proletarskoe GCF; 13 - Bogatoyskoe GCF; 14 - Leventsovskoe GCF; 15 Shebelinskoe GCF; 16 - Sev.-Korobochkinskoe OGF; 17 - Korobochkinskoe GCF; 18 - 
Gashinovskoe OF; 19 - Vishnevskoe GCF; 20 - Spivakovskoe GF; 21 - Drugelyubovskoe OGCF; 22 - Drobyshevskoe GCF; 23 - Evgenyevskoe GF; 24 - Trekhizbenskoe GCF; 25 Kondrashevskoe GCF; 26 - Olkhovskoe GCF; 27 - Markovskoe GCF; 28 - Lvovskoe OGF.

The estimate of the probability of $\mathrm{CO}_{2}$ leakage through the wells of existing fields is defined in Table 1, where areas of promising areas of $\mathrm{CO}_{2}$ geological storage and areas of oil and gas deposits are taken into account, it is considered that there are a large number of abandoned and operating wells in the fields, and the shafts and drifts of coal mines were previously excluded from areas of promising areas of $\mathrm{CO}_{2}$ geological storage.

Table 1. The probability of $\mathrm{CO}_{2}$ leakage through the wells of existing fields

\begin{tabular}{|c|c|c|c|c|c|c|c|c|}
\hline Site number for $\mathbf{C O}_{2}$ geological storage & $\mathbf{1}$ & $\mathbf{2}$ & $\mathbf{3}$ & $\mathbf{4}$ & $\mathbf{5}$ & $\mathbf{6}$ & $\mathbf{7}$ & $\mathbf{8}$ \\
\hline The area of the prospective site, $\mathrm{km} 2$ & 4425 & 4373 & 1630 & 1594 & 3311 & 1995 & 2712 & 9641 \\
\hline The area of fields on the site, $\mathrm{km} 2$ & 65,7 & - & 47,3 & 45,1 & 212,9 & 16,0 & - & 90,3 \\
\hline The probability of leakage of CO2, \% & 1,5 & - & 2,9 & 2,8 & 6,4 & 0,8 & - & 0,9 \\
\hline
\end{tabular}

Positions 13, 14 and 15 in Fig. 3 conditionally reflect the third scenario of $\mathrm{CO}_{2}$ leakage through existing faults and cracks in mountain formations (13), where gaseous $\mathrm{CO}_{2}$ rises along tectonic structures of a given area to groundwater (14), affecting their quality, and going to the surface (15), affecting vegetation, animals and humans.

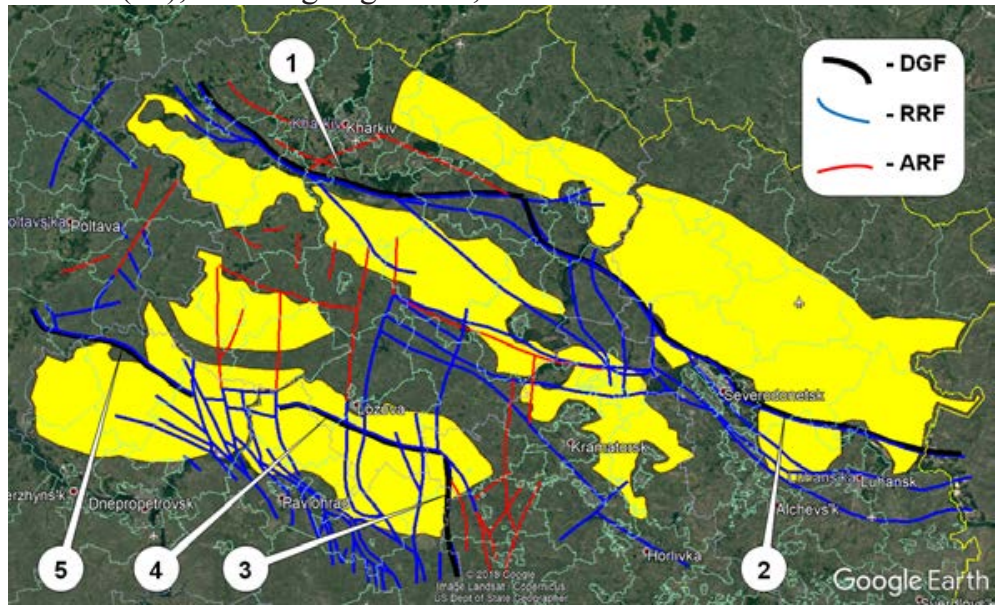

Fig. 5. Localization of deep geological (DGF), reliable (RRF) and alleged regional (ARF) faults

To assess the likelihood of the implementation of the third scenario of $\mathrm{CO}_{2}$ leakage from promising areas of $\mathrm{CO}_{2}$ geological storage in Donbass, you can combine the location of deep and regional faults [10] with geological sites (Fig. 5), which show the following deep geological faults: 1 - South-Kharkiv fault; 2 - Krasnoretsky fault; 3 - Krivoy-RogPavlovsky fault; 4 - Yurievsky fault and 5 - Golubovsky-Mikhailovsky fault, as well as other reliable and suspected regional faults in promising areas of $\mathrm{CO}_{2}$ geological storage. If we assume that the zone of $\mathrm{CO}_{2}$ leakage through geological faults is on average $1 \mathrm{~km}$ wide, then an estimate of the probability of such a $\mathrm{CO}_{2}$ leakage can be presented in Table 2.

Table 2. The probability of $\mathrm{CO} 2$ leakage through geological faults

\begin{tabular}{|c|c|c|c|c|c|c|c|c|}
\hline $\begin{array}{c}\text { Site number for CO2 geological } \\
\text { storage }\end{array}$ & $\mathbf{1}$ & $\mathbf{2}$ & $\mathbf{3}$ & $\mathbf{4}$ & $\mathbf{5}$ & $\mathbf{6}$ & $\mathbf{7}$ & $\mathbf{8}$ \\
\hline The area of the prospective site, $\mathrm{km} 2$ & 4425 & 4373 & 1630 & 1594 & 3311 & 1995 & 2712 & 9641 \\
\hline Area of possible CO2 leaks, km2 & 310 & 439 & 80 & 5 & 262 & 150 & 9 & 142 \\
\hline The probability of leakage of CO2, \% & 7,0 & 10,0 & 4,9 & 0,3 & 7,9 & 7,5 & 0,3 & 1,5 \\
\hline
\end{tabular}


As an example, assessing the impact of $\mathrm{CO}_{2}$ leaks on groundwater quality is compatible (Fig. 6) the contour of the promising area of geological storage of $\mathrm{CO}_{2} \mathrm{~N} 8$ (1) with a hydrogeological map of Ukraine (first from the surface of aquifers) [11] showing aquifers: in the Eocene, Oligocene and Miocene (2); in the fracture zone of the Marl-Cretaceous stratum of the Upper Cretaceous (3); in the upper and modern estuary sediments (4); in the deposits of the Jurassic (5); in Triassic sediments. Also in Fig. 6 shows the bed of the Seversky Donets River (7) and its tributaries (8). At the same time, $46.7 \%$ of the horizon 2 , $43.0 \%$ of horizon 3 , and $40.9 \%$ of horizon 4 fall within the territory of section N8, which indicates a significant impact on all aquifers of possible $\mathrm{CO}_{2}$ leaks in section N8.

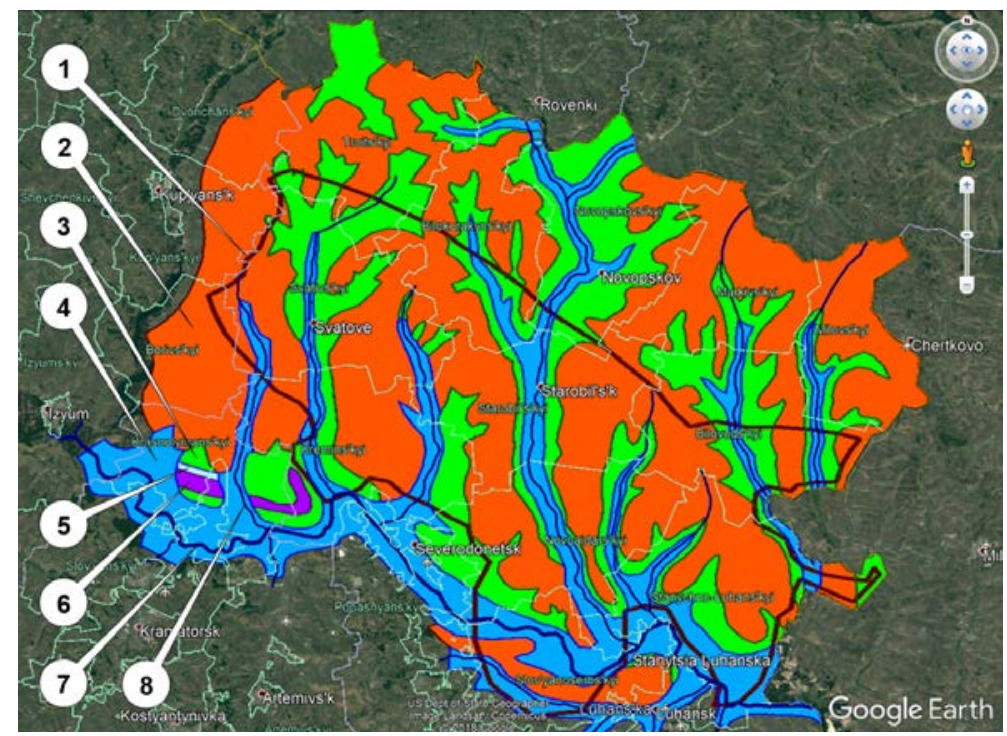

Fig. 6. The first aquifers from the surface in the territory of a promising area of storage of $\mathrm{CO}_{2} \mathrm{~N} 8$

Similar estimates for the first aquifers in the territory of other promising areas of the geological storage of $\mathrm{CO}_{2}(\mathrm{~N} 1-\mathrm{N} 7)$ can be made on the basis of data from this map [11].

A study of the scenarios and risks of $\mathrm{CO}_{2}$ leakage during its geological storage in the Donbass area will allow for measures to be taken to comply with environmental safety measures when implementing carbon dioxide capture and storage technologies to mitigate the effects of global climate change.

\section{References}

1. IPCC, 2014: Climate Change 2014: Mitigation of Climate Change (Cambridge University Press, 2014)

2. The Global Risks Report 2017, $12^{\text {th }}$ Edition (WEF, 2017)

3. IPCC Special Report: Carbon Dioxide Capture and Storage - Summary for Policy Makers and Technical Summary (IPCC, 2005)

4. Technology Roadmap - Carbon capture and storage (IEA, 2010)

5. COAL ATLAS: Facts and figures on a fossil fuel - 2015 (Heinrich Boll Foundation, 2017)

6. Negative Emissions Technologies and Reliable Sequestration: A Research Agenda (The National Academies Press, 2019) 
7. N.S. Shestavin, F.V. Nedopekin, V.V. Osetrov, V.V. Yurchenko, Low-carbon opportunities for the industrial regions of Ukraine (South-East, 2015)

8. N.V. Zhikalyak, V.V. Osetrov, N.S. Shestavin, Evaluation of $\mathrm{CO}_{2}$ capture and storage in the Paleozoic sedimentary sediments of Donbass, Collection of scientific works of the Institute of Geological Sciences of the NAS of Ukraine, 5, pp. 53-61 (2012)

9. Li Xiaochun, Coupled Thermal-Hydrodynamic-Mechanical-Chemical (THMC) Processes in $\mathrm{CO}_{2}$ Geological Storage (Institute of Rock and Soil Mechanics Chinese Academy of Sciences, 2017)

10. A.V. Zagorodnov, Criteria for the location of oil and gas deposits in the DnieperDonets Basin, taking into account salt tectonics, Bulletin of Kharkiv National University of V.N. Karazin, Series "Geology. Geography. Ecology”, 44, pp. 16-26 (2016)

11. Hydrogeological map of Ukraine (first from the surface of aquifers), URL: http://evoda.cc.ua/im/gl.jpg (28.06.2019) 